\title{
Unintended volunteers: The volunteering pathways of working class young people in community sport
}

Sport has become a major setting for youth volunteering in the UK. Volunteering has become understood as a means of enhancing responsible citizenship and of adding various capitals to young people's identities. Much research on young people's volunteering in sport has typically (and sometimes by default) focused on middle class experiences, highlighting the combination of instrumental and altruistic motives for volunteering, the importance of family and school in decisions about volunteering and its perceived longer-term benefits. This article focuses on the experiences of young working class volunteers and is based on an evaluation of five community sport projects that were part of the StreetGames Building a Participation Legacy from the London 2012 Olympic and Paralympic Games in Disadvantaged Areas initiative. Data from a combination of semi-structured interviews and focus groups were analysed to understand working class young people's volunteering pathways, including their initial engagement, motives and understandings of challenges and benefits. The findings from this study indicate that, in contrast to middle class young people, these young people's routes into volunteering were not part of a strategic career plan, but occurred contingently and with support from coaches. Young people subsequently suggested that volunteering and its scope for gaining formal training helped them to develop skills associated with desirable forms of social and cultural capital that might lead to labour market attachment, particularly in sport. These findings have important implications for understanding how social class shapes pathways into youth volunteering in the UK and for developing appropriate policy to encourage a wider range of young people to volunteer.

\section{KEY WORDS}

Volunteering

Young people

Community Sport

Community Coaching

Social Capital 


\section{Unintended volunteers: the volunteering pathways of working class young people in community sport}

Sport's enormous popularity has led to it becoming a primary setting for volunteering in the UK. In 2002, some 5.8m volunteers, including young people, sustained the work of over 106,000 English sports clubs (Sport England 2002). Research specifically related to young people and volunteering in sport related activities has drawn predominantly on the experiences of middle class young people in formal settings (Eley and Kirk 2002, Kay and Bradbury 2009), obscuring many young people's contributions to a range of organisations in their local communities and to civil society generally. The extent to which these young people may gain beneficial experiences that, if properly recognised, could support their social, cultural and economic well-being has been largely ignored outside of organisational reports and anecdotal evidence. Understanding how working class young people become volunteers in community sport and their understandings of the volunteering experience could contribute to enhancing opportunities to recruit and sustain their involvement.

This article analyses the experiences of working class young people who volunteer in community sport. It considers their pathways into volunteering, drawing on research from a project conducted by the National Charity StreetGames, established to assist local sports organisations to develop their capacity to provide sport in disadvantaged communities. The project was titled Building a Participation Legacy ${ }^{1}$ from the London 2012 Olympic and Paralympic Games in Disadvantaged Areas (authors 2013) and provided funding to five community based sports programmes ${ }^{2}$ engaging working class young people and using the StreetGames 'doorstep sport' approach to offering accessible and affordable activities in an informal way. The social class background of the volunteers locates the article within current debates about class and dis/advantage and volunteering's capacity to supplement formal accreditations with other modes of distinction (for example, social

\footnotetext{
1 The funder designated the title of the project. We are familiar with the critiques associated with the concept of legacy in this paper and are not claiming that the volunteering activities discussed in this article constitute a legacy.

2 The five community sports programmes were chosen by StreetGames on the basis that they are areas of high deprivation, including those with 'hard to reach' and multi-ethnic communities (Office for National Statistics 2010).
} 
and cultural capitals). Volunteering, for example, is a key avenue for middle class young people to accumulate the capitals that help to maintain their advantage in a competitive higher education system and labour market (Ball 2008). This is reflected in the youth sport volunteering literature. Previous studies have tended to focus on young people with prior experience of formal volunteering, who hold relatively high educational aspirations, or who make an active choice to volunteer prior to involvement (Kay and Bradbury 2009). By contrast, the communities chosen for this research were characterised by dense and locally focused social networks in which experiences of participation were likely to be constituted in 'helping out' in community activities, rather than as part of 'getting on' (Hardill et al. 2007, p. 399; Roberts and Devine 2004). This article, therefore, contributes to the currently limited literature on social class and volunteering and, more specifically, contributes to the under-researched area of young working class volunteers in sport.

It seems to us that the volunteering discussed in this article is underrecognised and its contribution to maintaining the civic domain is obscured. This research has implications for increasing our understanding of the nature of youth volunteering in the UK, for social policy in relation to youth volunteering and for broader questions of social inclusion.

\section{UK social policy and youth volunteering}

The principle of voluntarism is central to liberal democracy. It evokes notions of selforganisation, freedom and autonomy and has long been regarded as virtuous, the mark of a vibrant civic domain and fundamental to the effectiveness of social policy, especially in education and social care (Finlayson 1990, Hinton 1998, Brewis 2009). Since the inception of the welfare state, various policy regimes have incorporated voluntary action and volunteering as central features of liberal governance, assuming a correlation between civic engagement, social cohesion and, recently, social capital, although hard evidence for such links appears ambiguous (Grenier and Wright 2003). The evidence of impact of volunteering on volunteers themselves has been similarly limited although it is suggested that it can increase volunteers' sense of agency, contribute to their cultural capital in terms of skill development, add to volunteers' stocks of social capital and, in the American literature especially, contribute to socalled pro-social attitudes (Hamilton and Fenzel 1988, Uggen and Janikola 1999, Baines and Hardill 2008, Adams and Deane 2009). Investment in UK youth 
volunteering over the last decade or so has been considerable (Hill and Stevens 2010) and a broadly communitarian agenda has emerged in which volunteering has become understood as a means of securing the enhanced responsibilisation of young people. The New Labour government of the early 2000s invested significantly in youth volunteering. This had two broad aims. First, youth volunteering was to be a revitalising cure-all for a declining civic domain, in which young people were to be encouraged to play a full part. Second, volunteering would also support youth's labour market transitions at a time when those were becoming problematic across Europe (Matthews et al. 2009). The Russell Commission for example, embodying New Labour's close ties with the corporate sector, saw volunteering as a "route to skills and qualifications" as well as a means for young people to become more involved in their communities (Hill and Russell 2009, p.1).

Significant policy continuity existed between New Labour and, from 2010, the Coalition government over youth volunteering, and the organisation ' $\mathrm{v}$ ', established under New Labour, attracted on-going (but declining) financial support from the Coalition. The Coalition's so-called Big Society discourse had its youth focus in the National Citizen Service (NCS), established in 2010, in which volunteering was a central theme. Policy-wise, this suggests an emphasis on volunteering supporting citizenship and social cohesion rather than labour market transitions, and the NCS aimed to "... help young people become more engaged in their communities and develop their skills and knowledge to sustain that involvement" (Department for Education 2011, p. 2). The NCS offered 90,000 places in 2014 through which young people were supported in becoming involved in various community service initiatives. The Coalition's youth policy framework Positive for Youth drew attention to how volunteering can enable young people to "... shape their own lives and be positive influences in the lives of their peers..." (HM Government 2011, p. 13). These UK policy initiatives suggest significant commonalities in seeking to enhance responsible citizenship as well as adding capital of various kinds to young people's identities. They also share a common basis in which youth volunteering has become increasingly formalised and commodified.

\section{Volunteering, commodification and social difference}

Historically, the principal forms of English voluntary activity have been charity in the form of philanthropy, or mutual aid through collective action, although the boundaries 
between these are not always clear (Harris and Bridgen 2007). Volunteering is often understood on a spectrum between formal and informal involvement (Adams and Deane 2009, Department for Communities and Local Government 2010), as productive, collectively organised and guided by moral or ethical imperatives. Hustinx (2001), drawing on the work of Giddens and Beck, suggests that processes of individualisation associated with late modernity mean that young people's motives for volunteering are now framed less by a (traditional) notion of service reflecting a commitment to social solidarity, than by developing and maintaining a reflexive self project. Volunteering, thus, inevitably entails degrees of self-interest. In the UK, volunteering is invariably construed as unpaid, part time formal activity, often having an altruistic element and located in the public or civic domain (Anheier and Salaman 1999). The focus on altruism ignores any instrumental motives for volunteering and volunteering was recently defined as “... any non-compulsory activity which involves spending time, unpaid, doing something which is of benefit to others (excluding relatives), society or the environment" (Hill and Russell 2009, p. 2). Youth volunteering's prominence has increased by becoming structured and regulated through the activities of high-profile youth volunteering organisations (for example, Community Service Volunteers, Voluntary Service Overseas, vInspired) dedicated to providing opportunities for young people to gain cultural and social capital through their activities. These organisations have constructed normative pathways that shape understandings of young people's entry into and their experiences of volunteering.

UK Government research on volunteering consistently indicates that affluent groups are more likely to volunteer than their less affluent peers (National Centre for Social Research 2011). However, the relationship between social class and volunteering may be impacted by other factors: gender (National Centre for Social Research 2011), ethnicity and religion (Bennett and Parameshwaran 2013). The tendency for individuals from higher social class groups to be more likely to volunteer has been shown to apply to young people's volunteering generally (Bennett and Parameshwaran 2013) and in sport contexts particularly (Eley and Kirk 2002, Sport England 2002, National Centre for Social Research 2011). While enhanced social and human capital have been discussed quite widely as possible outcomes of volunteering, it is also useful to consider how capital may shape young people's entry into volunteering. Social capital, in particular, has been the focus of extensive 
research on civic engagement and participation, and individuals' links to organisations increase the likelihood of volunteering. In a study of volunteering in Europe, $66 \%$ of individuals were members of the organisation in which they volunteered (Gaskin and Smith cited Anheier and Salaman 1999). According to Lee and Brudney (2012) social capital impacts volunteering in three key ways: individuals who are socially connected to their communities realise more benefits from volunteering, volunteering is linked to group affiliation and identity, and being part of extensive social networks increases the chance of being asked to volunteer. Schooling and sport represent two social networks that young people access and, according to the Helping Out Survey, conducted by the Institute for Volunteer Research, educational organisations were the most popular destination for young volunteers in the UK (43\%) followed by sports and exercise organisations (26\%) (Hutin 2008). These findings have implications for young people's motives for volunteering. Furthermore, the National Youth Agency (2007) found that young people are most likely to volunteer in activities that confirm their sense of identity and personal interests. Group affiliation and involvement in leisure organisations, therefore, can be shown to influence young people's patterns of volunteering. Barriers to youth volunteering in sport are, apparently, connected with levels of commitment required, volunteering being associated with distinct groups, a lack of awareness of opportunities and the potential benefits of sport volunteering (Mawson and Parker 2013). All these factors are likely to comprise social class aspects.

Family is an important source of capital and young people whose parents volunteer are more likely to volunteer themselves (Eley and Kirk 2002, Bennett and Parameshwaran 2013). One study of European volunteering found that $44 \%$ of volunteers learned about volunteering through family and friends, while $27 \%$ volunteered as a result of being a member of an organisation (Gaskin and Smith, op cit). Dean suggests, that one explanation for class-based differences in volunteering is that middle class habitus, centred on family, creates those young people's selfconfidence in participating as volunteers (Dean 2013). Dean's research supports other work that highlights the importance of social and cultural resources, friends and family on volunteering behaviours. 
The value of volunteering has been widely debated. There is a history of sport projects claiming improved social and economic outcomes for young people in working class communities through developing new skills, knowledge and social resources (Coalter 2007). Sports participation may reinforce or activate new encounters, networks and social ties that might, in turn, help young people develop their learning or support their labour market aspirations (Nicholson and Hoye 2008). Social connections made through sports volunteering may therefore act as tangible resources with the potential to contribute to improving young people's lives (National Youth Agency 2007). Although researchers have urged caution in assuming that sport can automatically provide the social and personal outcomes that are linked to participation, national and international youth programmes use sport in attempting to achieve their goals (Nichols 1997, 2004, Coakley 2002, Sandford et al. 2006). As in the case of StreetGames, programmes that use sports to attain youth development outcomes often incorporate their capacity to develop volunteers as part of their aims and objectives and as a measure of their success.

\section{Research Background}

This article is based on findings from a two-year evaluation, Building a Participation Legacy from the London 2012 Olympic and Paralympic Games in Disadvantaged Areas. The evaluation sought to gain an understanding of how community sport projects might have a positive impact on young people in disadvantaged areas in England and Wales. The study assumed a qualitative methodology, drawing on narrative accounts offered by young people in focus groups and interviews (Griffin and May 2012). The data collection considered the extent, nature and value of volunteering in disadvantaged areas. Young people were encouraged to articulate their understandings of volunteering and the conditions and relationships that informed their volunteering pathways.

The study gained Brunel University Research Ethics Committee approval prior to researchers entering the field. Fieldwork was conducted in five neighbourhoods that had previously been identified as suitable sites for StreetGames initiatives. Twenty five visits were completed, nine of which were focused upon researching young volunteers who typically supported and organised sporting sessions, assisted at regional events, gained formal accreditations and learned how to 
coach sport and design youth-led activities. Volunteers were recruited to the research in consultation with local coaching staff who acted as gatekeepers. Information about the evaluation was widely distributed and in-depth discussions held with an adult the young people trusted so that each volunteer felt informed about the purpose and nature of the research (Rogers and Ludhra 2012). In total, twenty 13-18 year old volunteers participated in this part of the evaluation. The criterion for participation was that young people were currently volunteering in one or more of the StreetGames programmes. The young people had all been participants in a sport-based programme and began volunteering for about two hours a week, on average, six months prior to data collection, seven were female, five were from minority ethnic backgrounds and all attended local secondary schools and lived in the five neighbourhoods identified.

The analysis presented here draws on narratives from ten individual interviews and four focus groups. The focus groups consisted of nine of the young people interviewed individually and ten other participants. Interviews and focus groups lasted about 45 minutes, were carried out at times and in public settings with which the volunteers were familiar and were recorded and transcribed. These young people were chosen to gain information more specifically on the experience of volunteering and the interviews focused on their experiences with community sport, factors that encouraged them to begin volunteering, their perception of the experience of volunteering, perceived benefits of volunteering, challenges, and their future plans.

Based on the interviews, portraits of individual volunteers were created, enabling researchers to gain detailed accounts of the processes underlying their volunteering experiences. We were particularly interested in how stories of volunteering integrated with young volunteers' sense of self and their (working class) identities. The analysis was underpinned by Bourdieu's view that social orders are reflected or deposited in "durable dispositions such as mental structures" (1993, p.18). Representations of these structures ('the social') emerge through talk, through narrative accounts such as those from which we draw. A heuristic approach to analysis was employed to map some of the broad dimensions of working class youth volunteering experiences. Key aspects of the volunteering experience were therefore elicited from each portrait, and where possible, developed subsequently through the interactions of focus group members (Morgan 1997). We were keen to maintain both 
a holistic sense of the individual and to explore shared and different aspects of young people's volunteering. Our coding was informed by our broad theoretical interests in social class and social capital (Ball 2008). From the process of coding and analysis four key themes emerged that seemed to explain the characteristics that shaped the volunteering activities of the young people in this study: unintended volunteering, the importance of coaches, 'fittin in', and developing capital.

\section{Volunteering pathways}

The aim of this research was to understand more about the volunteering experiences of young people from disadvantaged working class backgrounds. Our analysis elicited four key factors that we discuss below.

\section{Unintended volunteering}

Coaches working with the StreetGames' programmes recruited all of the volunteers involved in this research. Involvement was linked to the young people's enjoyment of the sports programmes and a nascent recognition that they could effectively help younger participants to have a positive experience. When asked how they became volunteers, the young people indicated that their volunteering was unplanned and invariably instigated by a coach. Their volunteering was initially unrelated to parental or school encouragement or strategic forms of capital building.

Dunno, really... erm ... (the coach), just like asked if we (a friend and him) could help out...like help him do that and this (set up, organise cones)... he said like, "why don't you help us out on another night too cos' you are helping me out now anyway". So like we did...It is not a big deal. (Ethan, 17)

The data extract shows how Ethan saw volunteering as part of day-to-day leisure life, nothing special, just ordinary and no 'big deal'. This is volunteering constituted in no more than 'helping out' and it resonates with ideas of belonging in this organisation and community.

Young people often withdraw from organised sports in their mid to late teens and volunteering was used as a way to keep young people involved in the programme 
and offer them what was understood to be an age-appropriate role within the organisation.

I just enjoyed the sessions and I just thought it would be good to help the younger kids enjoy the sessions like I did...well, at the beginning [the coach] told us we could volunteer instead of...stopping coming so I was like, OK! I mean, I have known ... [the coach] for like years an' that now and I didn't want to stop coming here (to the sessions), so I thought, yeah, I want to do coaching. (Emma, 17)

Interviewees described their initial engagement in volunteering as an outcome of their interest in a particular sport, their relationship with the coach and the programme, and a desire to help others to enjoy the programme. A sense of affiliation and identification with an organisation has been shown to be a key influence on decisions to volunteer and suggests that community sports programmes can create spaces that afford young people a sense of belonging and where they can develop networks and relationships associated with enhancing social capital (Anheier and Salaman 1999, Weiss and Stuntz 2004, Lee and Brudney 2012). This, in turn, may be an important precursor to further volunteering activities. Being in a position to be invited to volunteer is one of the ways social capital enhances the likelihood of volunteering (Lee and Brudney op cit).

The parents of the young people involved in this research played a limited role in supporting and managing their volunteering activities. Indeed, none of the respondents in this research had a parent who volunteered or recalled having a discussion about volunteering at home:

I don't think [my parents] really care [that I volunteer], to be honest. I never say much to them about it. I think, they just maybe think I'm trampolining an' that. Like, they never ask except maybe if I am going out late. I just say I'm coming to the [sports] centre. (Sadie, 16)

Often, young people felt that their parents wanted to know where they were but were less concerned about the specific activities they were involved in. This differs markedly from research exploring middle class young people's volunteering which suggests that parents play a key role in prompting, managing, and supporting their children's sport and volunteering activities (Smith 1999, Eley and Kirk 2002). In 
particular, middle class families have been shown to identify sport and volunteering experiences as important spaces for the development of friendships, skills, character, and other forms of social and cultural capital that are perceived to underpin success in adulthood, constituting examples of 'opportunity hoarding' that thwart upward social mobility (McKnight 2015, p. 13). Volunteering can become strategically located in middle class youth biographies as a key aspect of transitions to successful adulthood (Holland 2007). Data from working class settings are important for the contrasting insights they give into the processes leading to initial engagements in volunteering and the apparently weaker instrumentalist orientation that shapes these young people's desire to volunteer.

\section{The importance of coaches}

Rather than parents and teachers, sports coaches were perceived as crucial to these young people's initial and sustained engagement in volunteering. Young people's willingness to commit to volunteering was linked with positive experiences in the programme and their perceptions of the coach as helping them in the past and a desire to reciprocate this. This is important in that it further embeds the practice of volunteering in the networks of social exchange that shape local neighbourhoods.

It is important to help younger kids who don't enjoy [sport] to enjoy it ... but, I just enjoy helping out the most...helping the younger kids to enjoy themselves. I mean, you have got to help out 'cos [the coach] an' that helped me when I first came here. (Emma, 17)

This sense of obligation intersects with instrumental and altruistic motivations for volunteering and was, in this instance, shaped by young people's relationships with their coaches. These relationships developed over time and participants described in detail the qualities of the coach that were important to them and that led them to consider volunteering. For example, young people suggested that these relationships included friendship, "He is more like a mate" (Michael, 17); and feelings of mutual respect, “... [Coaches] are friendly and fun, and they won't tell you off, even if you do something wrong” $(A l i, 14)$. Coaches were also seen as easy to speak to: “... they are still professional but they are so chilled out you feel like yeh can talk to them about normal stuff and what's going on really" (Aiden, 16). Coaches often came from the 
same neighbourhood as participants and their approach clearly resonated with the habitus of the young people.

The professionalism and leadership qualities of coaches were acknowledged, alongside the more personal elements of the relationships that were particularly valued by young people. This complex combination was framed in terms of a narrative of informality and the nature of these relationships was often presented in contrast to those they had with teachers.

Well, you just get along with them (coaches) an' that talk about what you have been doing like 'cos most teachers you can't speak to like that and not about like what you are doing you can only speak about the lessons and like school stuff 'cos some get stressed at ya... (David, 16)

The young people suggested that relationships with coaches tended to be personal, almost familial, often contrasting with the hyper-rational rules prevailing at school. These relationships appear to be effective as vehicles for helping young people to become creatively involved in the practices of everyday life in their communities. In short, StreetGames coaches appear to represent what Schudson (1996) calls the "civic spark plugs" that help to broaden public participation. The democratic, informal coaching style clearly contrasted with authoritarian forms of leadership associated with teachers and those experienced in more formal club sport and team contexts (Grossman 2006, Coalter 2008). The need for sports programmes to provide young people with a space that values self-determination, decision-making and responsibility has been widely documented (Coakley 2002, Eley and Kirk, 2002, Sanford et al. 2004).

\section{"Fittin' in": the informal culture of StreetGames sessions}

Throughout the data, evidence emerges that StreetGames sessions played a pivotal role in the development of a zone of social energy; a space that provided an alternative to other sporting contexts, viewed by some young people as overtly competitive, restrictive, and formal. This environment was perceived to foster particular benefits for young people in terms of increasing their enjoyment of sport, providing positive social experiences and enhancing self-confidence. The following 
extract from a volunteer focus group illustrates how StreetGames' activities were understood to offer a relaxed and less competitive sporting environment:

Yeah, like here you can just chill out and have a kick about. In P.E. like, you have to improve and get a better level and impress the teachers and your mates an' people like that...you can just chill here an' you don't need to worry about all that. (David, 16)

One young woman told us that this relaxed space encouraged her to develop her sporting interests:

I used to hate sport 'cos my Sister was good at sport and the only thing I was better than her at was football. I was better academically but teachers used to say to me, 'so you will be good at trampolining then' and, you would be like 'no', so I used to just avoid doing it but now volunteering means I enjoy [sport]. (Emma, 17)

Absence of pressure, having fun and the chance to be with or chill with friends structures young people's sense of identification with sports sessions, as one volunteer suggests in an interview:

Getting to join in and being with your friends having a laugh an' that an like helping out [during the session] an' that but like not like [helping out] all the time just making sure everyone gets a turn and like teaching the younger ones to do stuff like just helping them. (Carl, 17)

Young people were keen to ensure that they helped to maintain the relaxed atmosphere of sessions in their new leadership roles. The interplay of informality and both sporting and social interests in the sessions often led to a sense of belonging:

...it's like different like when I am in school like you are nothing there but here you feel special, like an adult and you feel like you fit here, like being with all you friends and like people being nice to you an' that. (Paige, 15)

References to interviewees 'feeling special' and 'fitting' are interesting, suggesting a sense of belonging in the space where they have 'a feel for the game' and can potentially begin to develop confidence and leadership skills. This is emphasised by the sense that they are offered the status and respect of adulthood in contrast to experiences at school where 'you are nothing'. 


\section{Developing capital through volunteering?}

The young people we interviewed reported that their volunteering experiences yielded personal and social benefits as they came to form identities as leaders and volunteers, often re-imagining themselves in the light of their developing skills. Elements associated with capital-building included engaging in positive activities, developing work-related skills, and increasing knowledge and confidence through training, experience and self-reflection. These are important capacities that formal education often struggles to achieve with marginalised working class young people (Archer, Hollingworth and Mendick 2010, Hayes 2012).

The young people in this study viewed the experience of volunteering as a welcome positive alternative to other leisure activities.

I suppose it breaks the mould that I am here on Friday nights...whereas everybody else will probably be drinking, probably, and I enjoy it... I would rather be here than standing out in the cold drinking...like a lot of them kids (participants), if they didn't come here, they will just end up doing that. (Emma, 17)

[Volunteering] is a start, ya know, and I think you have to keep going in one direction and not the other way, back to where I was.(Asha, 18)

For these young people, volunteering was a new experience associated with positive behaviours and included the potential transformation of negative peer group influences and behaviours into something more vital and future-oriented. As such, it challenged negative stereotypes of youth peer groups. These experiences are arguably supportive of transitions into a citizenship that is defined, at least partially, by its contributions to the fabric of community. So often, these remain unrecognised outside of formally organised volunteering and practices of citizenship.

Some of the young people reflected on their new leadership roles and their positions as role models for younger participants:

...when I am with younger people I kinda speak more formally towards them. Whereas at home with my friends I can speak normal, 
like slang 'cos they understand us...if I speak slang to the younger kids they might go home and speak slang to their parents...I don't want to set a bad example towards them... (Paige, 15)

The capacity to be a good leader was a source of pride and confidence, both in terms of their own capacity for leadership and the trust of being given a position of responsibility. According to Martinek, Shilling and Hellison (2006), fostering the development of socially responsible young leaders requires strategies for empowering young people through providing them with opportunities to build confidence, to make choices, and to engage in decision-making as well as being involved in peer teaching. Peer teaching involves the gradual development of leadership skills by providing young people with opportunities to practice coaching in a variety of formats that match their experience and skills. StreetGames coaches seemed to provide these types of confidence-building experiences quite informally by initially asking participants to help out, gradually adding responsibilities and, ultimately, offering training. Under their coaches' guidance this enabled the volunteers to devise an informal pedagogy that had considerable potential in supporting the volunteers' own transitions and contributing to the lives of the young people they worked with.

It's good like knowing you can take a session and you have been given the responsibility to do it and [coaches] trust you to do it. It like gives a good feeling inside, like a proud feeling when you have coached someone how to do something new. (David, 16)

Running sport sessions also contributed to young people's practical leadership skills. Olivia's experience encouraged her to reflect on and empathise with younger participants' experiences:

...yeah, well [volunteering] teaches you how to run a session and how to control them if you get stuck too. Sometimes you have just got to try and, calm them (the participants) down, sit with them 'cos they are frustrated. ... I just put myself in the position of what would I feel like it was happening to me.... (Olivia, 16)

Perhaps one of the most exciting findings from this research was young people's own accounts of the skills and confidence that they developed through volunteering being transferred to other domains. When asked what they had learned as volunteers, the following observations were common: 
...it helped me have confidence really. I think it helps you be confident talking to people like teachers 'cos like you 'av to speak to adults, like coaches an' that all the time. (Ethan, 17)

Just like running a football group I couldn't really do before... I mostly do reffing an' that now but I think I learned loads from [coach]. Setting up an' helping out with different things so you know what to do...I'm now a qualified referee. (Michael, 18)

I have picked up confidence in speaking to other people and feel confident talking to a big group. I have learned to take responsibility and now feel ok in like, difficult like challenging situations. (Sarah, 17)

The positive association of volunteering with desirable forms of capital was also, apparently, recognised by teachers:

[Volunteering's] good 'cos you get [StreetGames] T-shirts that says you are a volunteer and that's good. I wear mine all the time like to P.E. an' that now cos' it makes [teachers] aware of what you do. Like, teachers see me wearing my shirt and are like interested in that. [Teachers] never really spoke to me before! (Ali, 14)

The experiences of the young people interviewed here indicate that they often feel distanced from teachers and the organisational styles and practices of school. However, their experiences of working closely with adults, gaining empathy and meeting the demands of leadership provided these young people with social confidence. In turn, the recognition and valuing of the role of volunteer by teachers provided tangible evidence for these young people themselves of their potential social gains.

Several young people commented on the impact that volunteering at the sessions had on employment prospects. For some young people interviewed, the idea of career (rather than simply being in a job) seemed alien. However, there was evidence of the coaches scaffolding educational and employment aspirations, perhaps reflecting some of the instrumentalism that characterises formal volunteering amongst middle class young people (Matthews et al. 2009). Clearly some of these young people recognised the potential their volunteering had for achieving recognition and of creating possible attachments in career-oriented areas of the labour market, 
particularly in sport itself. Interestingly, none of the young people identified their knowledge and skills as transferable beyond sport. As Ethan and Emma stated:

I want to work in sport like doing what ... [the coaches] do some day cos I think I would enjoy it (being a Sport Development Officer)...like getting paid to do sport an' that.. I mean, I didn't really think about what I'd do for a career and I never thought about coaching football or that cos like it was always just for a laugh or just a way to see mates an' that...I don't think school helped. I mean, like choosing a career an' that cos' like, I didn't see the point (in school). I mean, most teachers never liked us much anyway. (Ethan, 17)

...like, I wouldn't have done sport in A-level if I hadn't started volunteering. I didn't do it in GCSE but after doing all this it made me a lot more interested in sport...I enjoy the coaching and like the sports development side of it. I mean, you don't need to be good at sport here. I mean, here you try different sports and that's good. (Emma, 17)

Although, employability was not the primary reason for initially becoming involved, some young people linked their volunteering activities to possible future labour market attachment, "[volunteering] would look good on a C.V." (Sarah, 17). For the young people involved in this study, volunteering provided opportunities for developing skills and confidence associated with leadership. This included organising sports sessions, gaining qualifications, and reflecting on the demands of planning and providing sport for other young people. The development of leadership skills, confidence, and an increasing awareness of employment options led to identifying tangible choices about educational and labour market aspirations for some of these young people. Significantly, a progressive culture was developed in these sport settings where some of the younger participants were starting to look up to these young volunteers and follow their lead into volunteering:

I...like helping out the volunteers... like sort of looking up to people who were helping out. (Sadie, 16)

If you are short of a man [the older volunteers] will go in [goal] for ya and help you out... and they are older an' that an' well, they are a bit of an idol aren't they, so, like it makes you want to do something with volunteering. (Chris, 13) 
The combined impact of the enjoyment of the sport sessions, the informal environment, the opportunity to undertake leadership roles and build trusting relationships with adults equipped young people with the skills and knowledge that made them effective volunteers. The development of forms of social and cultural capital was facilitated by the embeddedness of StreetGames programmes within the young people's own social and cultural landscapes providing a comfortable and effective pathway into volunteering. Local networks and extant accumulated stocks of social trust and respect that provide the social foundations of local communities shape these pathways which, in turn, add to these resources. They potentially strengthen local ties and create further opportunities for the practice of good citizenship.

\section{Discussion and conclusion}

Processes of commodification have increasingly bureaucratised and professionalised youth volunteering in the UK, attracting criticism from politicians and some volunteer organisations (Cabinet Office 2012, Volunteering England 2012). However, voluntary activity and volunteering that does not conform to the commodified version (like that discussed here) or which does not occur through or within recognised organisational frameworks has, we suggest, become obscured in debates about the value of youth volunteering. Indeed, much volunteering especially that which occurs 'under the radar' in working class neighbourhoods (Dean 2013, p. 57) remains contingent, almost inadvertent, probably invisible and mostly unrecognised beyond its immediate local setting. This suggests the possibility of important classed distinctions between voluntary activities undertaken by people located in different social and material spaces. Perhaps the main point is to understand that the social relations that underlie any specific setting shape volunteering, and the “... particular patterns of social organisation and social networks in which people find themselves" (Hardill et al. 2007, p. 399) form pathways into and through voluntary work. Furthermore, the young people interviewed here derived much pleasure from their attachments to the StreetGames projects. This dimension can be forgotten in the somewhat earnest approach often taken to volunteering and to citizenship training generally. As the young people here indicated, involvement in volunteering can be enormous fun.

More specifically the working class young people in this research could be characterised as unintended volunteers whose recruitment developed contingently through their engagement in community sports programmes. Their progression to 
volunteering was facilitated by the supportive informal environment of the sports programme and the presence of an encouraging adult with whom they had a trusting relationship. This volunteering pathway differs from much of the literature that suggests that parental influence and schools play a key role in forming young people's choices about volunteering. Such routes into volunteering would have been unlikely choices for young people who, typically, identified school as a stressful, alienating environment and whose parents neither volunteered nor initiated volunteering activities themselves. However, constructing and managing these informal pathways is time-consuming and messier than the recruitment strategies adopted in formal volunteering organisations that have received Government support. Our research suggests the importance for these young people of developing an on-going relationship with a particular coach or coaches whose initiative encouraged them to become increasingly involved as volunteers. In policy terms, it might be useful to consider whether a leadership programme that systematically provides young people with opportunities to engage in leadership activities might inspire more young people from various backgrounds to try volunteering even in the absence of a longer term affiliation with a programme (Martinek, et al. 2006). This means that local organisations like youth clubs, voluntary groups and sports clubs provide vital social and material infrastructure to young people's pathways into volunteering. Cuts to such organisations in the current context of tightening UK austerity policy can only further damage the prospects of those living in disadvantaged communities (Beatty and Fothergill 2013). They, of course, are already suffering disproportionately from these policies.

The young people interviewed in this study indicated that they gained significantly from their volunteering experiences through increased social skills and heightened employment and educational aspirations that might extend beyond the community sport setting. These findings help to demonstrate the possible value of volunteering for young people from working class backgrounds. Interestingly, the young people themselves envisaged any potential future labour market attachments emerging through their volunteering as being specifically in the field of sport. Although further research is necessary, this contrasts with accounts of middle class volunteering in which benefits constitute a kind of 'transferable virtue' that has exchange value across the labour market. 
The work discussed here poses a challenge as supporting the informal pathways and achieving progression into volunteering is time consuming and unpredictable. Programmes or initiatives (like StreetGames) whose funding is dependent on quick recruitment and short-term demonstrations of cost-efficient outcomes will inevitably deploy more formalised procedures. Considering the needs and the habitus of working class youth, however, can help to build effective and inclusive volunteering opportunities. We argue that this addresses important questions of distributive justice and recognition (Fraser 2000) as existing patterns of middle-class volunteering have the potential to deny access to working-class young people by constructing pathways that fail to acknowledge class differences in habitus. Current political powers should take urgent steps to acknowledge this and consider how volunteering policy might contribute to securing recognition and, thus, potential redistribution for a wider spectrum of young people.

\section{References}

Adams, A. and Deane, J., 2009. Exploring formal and informal dimensions of sports volunteering in England. European Sport Management Quarterly, 9 (2), 119-138.

Anheier, H.K. and Salaman, L.M., 1999. Volunteering in cross-national perspective: Initial comparisons. Law and Contemporary Problems, 62(4), 43-61.

Archer, L. Hollingworth, S. and Mendick, H., 2010. Urban Youth and Schooling. Maidenhead: Open University Press.

Baines S. and Hardill I., 2008. 'At least I can do something': The work of volunteering in a community beset by worklessness. Social Policy and Society, 7(3), 307-317

Ball, S.J., 1993. Education markets, choice and social class: The market as a class strategy in the UK and US. British Journal of Sociology of Education, 14(1), 3-19.

Ball, S.J., 2008. The Education Debate. Bristol: Policy Press. 
Beatty, C. and Fothergill, S., 2013. Hitting the poorest places hardest: The local and regional impact of welfare reform [online]. Sheffield: Centre for Regional Economic and Social Research Sheffield Hallam University. , available from:

http://www.shu.ac.uk/research/cresr/sites/shu.ac.uk/files/hitting-poorest-placeshardest_0.pdf [accessed 22 October 2015]

Beck, U., 1992. Risk Society, Towards a New Modernity. London: Sage Publications

Bennett, M. and Parameshwaran, M., 2013. What factors predict volunteering among youths in the UK? Briefing Paper 102, TSRC. Birmingham: University of Birmingham. Available at:

http://www.birmingham.ac.uk/generic/tsrc/publications/index.aspx [accessed 22 October 2015]

Bourdieu, P., 1993. Sociology in question. London: Sage Publications.

Brewis, G., 2009. From working parties to social work: Middle-class girls' education and social service 1890-1914. History of Education, 38(6), 761-777.

Brooks, R., ed., 2009. Transitions from education to work: New perspectives from Europe and beyond. Basingstoke: Palgrave Macmillan.

Cabinet Office, 2012. Boost to volunteering as government cuts red tape [online]. Available from:

https://www.gov.uk/government/news/boost-to-volunteering-as-government-cuts-redtape. [Accessed, 13th December 2013].

Coakley, J. J., 2002. Using sports to control deviance and violence among youths. In M. Gatz, M. A. Messner and S. J. Ball-Rokeach, eds. Paradoxes of youth and sport. Albany, NY: State University of New York Press, 13-30.

Coalter, F., 2007. Sports clubs, social capital and social regeneration: 'ill-defined interventions with hard to follow outcomes'? Sport in Society, 10(4), 537-559. 
Coalter, F., 2008. Sport-in-development: Development for and through sport. In M.

Nicholson and R. Hoye, eds., Sport and social capital. Butterworth- Heinemann, 3960.

Dean, J., 2013. Manufacturing citizens: The dichotomy between policy and practice in youth volunteering in the UK. Administrative Theory \& Praxis, 35(1), 46-62.

Department of Communities and Local Government, 2010. 2008-09 Citizenship Survey: Volunteering and Charitable Giving. London: CLG.

Department for Education, 2011. National Citizen Service Discussion Paper. London: DFE.

Eley, D. and Kirk, D., 2002. Developing citizenship through sport: The impact of a sport-based volunteer programme on young sport leaders. Sport, Education and Society, 7(2), 151-166.

Finlayson, G., 1990. A moving frontier: Voluntarism and the state in British welfare 1911-49. Twentieth Century British History, 1(2), 183-206.

Fraser, N., 2000. Rethinking redistribution. New Left Review, 3, 107-120.

Giddens, A., 1991. Modernity and self-identity: Self and society in the late modern age. Cambridge: Polity Press.

Grenier, P. and Wright, K., 2003. Social capital in Britain: An update and critique of Hall's analysis, International Working Paper Series, 14. London: Centre for Civil Society, London School of Economics and Political Science.

Griffin, A. and May, V., 2012. Narrative analysis and interpretive phenomenological analysis. In C. Seale, ed., Researching Society and Culture. 3rd Ed. London: Sage Publications.

Grossman, J., 2006. Review of what youth programs do to increase the 
connectedness of youth with adults, Journal of Adolescent Health, 39(6), 788-799.

Hamilton, S. and Fenzel, L., 1988. The impact of volunteer experience on adolescent social development: Evidence of program effects. Journal of Adolescent Research, 3(1), 65-80.

Hardill, I., Baines, S. and 6, P., 2007. Volunteering for all? Explaining patterns of volunteering and identifying strategies to promote it. Policy and Politics, 35, 395-412.

Harris, B. and Bridgen, P., 2007. Introduction: The 'mixed economy of welfare' and the historiography of welfare provision. In B. Harris and P. Bridgen, eds. Charity and mutual aid in Europe and North America since 1800. Abingdon: Routledge, 1-18.

Hayes, D., 2012. Re-engaging marginalised young people in learning: The contribution of informal learning and community-based collaborations. Journal of Education Policy, 27(5), 641-653.

Hill, M. and Russell, J., 2009. Young people, volunteering and youth projects: A rapid review of recent evidence. Available from:

http://www.ivr.org.uk/images/stories/Evidence\%20Bank/v20formative20evaluation20 rapid20evidence20review20-20formated20-20Dec202009-1.pdf National Centre for Social Research: London [accessed 3 June 2014].

Hill, M. and Stevens, D., 2010. Measuring the Impossible? Scoping study for longitudinal research on the impact of youth volunteering. London: Institute for Volunteering Research.

Hinton, N., 1998. Voluntarism and the welfare/warfare state: Women's voluntary services in the 1940s. Twentieth Century British History, 9 (2), 274-305.

HM Government, 2011. Positive for youth: A new approach to cross-government policy for young people aged 13-19. Available from: https://www.education.gov.uk/publications/eOrderingDownload/DFE-001332011.pdf [accessed 23 October 2015]. 
Holland, J., 2007. Inventing adulthoods: Making the most of what you have. In H. Helve, and J. Bynner, eds. Youth and Social Capital. London: The Tufnell Press.

Hustinx, L., 2001, Individualisation and new styles of youth volunteering: An empirical exploration. Voluntary Action, 3(2), 57-74.

Hutin, M., 2008. Young people help out: Volunteering and giving among young People. London: Institute for Volunteering Research.

Kay, T. and Bradbury, S., 2009. Youth sport volunteering: developing social capital? Sport, Education and Society, 14(1), 121-140.

Lareau, A., 2002. Invisible inequality: Social class and childbearing in black families and white families. American Sociological Review, 67(5), 747-776.

Lee, Y. and Jeffrey L. Brudney, J.L., 2012. Participation in formal and informal volunteering: Implications for volunteer recruitment. Nonprofit Management and Leadership, 23(2), 159-180.

Martinek, T., Schilling, T. and Hellison, D., 2006. The development of compassionate and caring leadership among adolescents. Physical Education and Sport Pedagogy, 11(2), 141-157.

Matthews, N. Green, P. Hall, D and Hall, I., 2009. The role of volunteering in transitions from higher education to work. In R. Brooks, ed., Transitions from education to work. New perspectives from Europe and beyond. Basingstoke: Palgrave Macmillan, 150-166.

Mawson, H. and Parker, A., 2013. The next generation: Young people as sports Volunteers. In A. Parker and D. Vinson, eds., Youth sport, physical activity and play: Policy, intervention and participation. Abingdon: Routledge.

McKnight, A., 2015, Downward mobility, opportunity hoarding and the 'glass floor'. London: Social Mobility and Child Poverty Commission.

Morgan, D., 1997. Focus groups as qualitative research. 2nd ed. London: 
Sage Publications.

National Centre for Social Research. 2011. Understanding the drivers of volunteering in culture and sport: Analysis of the Taking Part Survey. London: DCMS.

National Youth Agency, 2008. Young people's volunteering and skills development, Research Report RW103. Available from:

http://webarchive.nationalarchives.gov.uk/20130401151715/http://www.education.go v.uk/publications/eOrderingDownload/RW103 [accessed 24 October 2015]

Nichols, G., 1997. A consideration of why active participation in sport and leisure might reduce criminal behaviour. Sport Education and Society, 2(2), 181-190.

Nichols, G., 2004. Crime and punishment and sports development. Leisure Studies, 23(2), 177-194.

Nicholson, M. and Hoye, R., 2008. Sport and social capital. Oxford: ButterworthHeinemann.

Office for National Statistics, 2010. The English indices of deprivation:

Statistical release. Available from:

https://www.gov.uk/government/uploads/system/.../1871208.pdf [accessed 20 May $2011]$.

Roberts, J. and Devine, F., 2004. Some everyday experiences of voluntarism:

Social capital, pleasure and the contingency of participation. Social Politics, 11(2), 280-296.

Rogers, C. and Ludhra, G., 2012. Research ethics: Participation, social difference and informed consent. In S. Bradford and F. Cullen, eds., Research and Research Methods for Youth Practitioners. London: Routledge. 
Sandford, R. A., Armour, K. M. and Warmington, P. C., 2006. Re-engaging disaffected youth through physical activity programmes. British Educational Research Journal, 32(2), 251-271.

Schudson, M., 1996. What if civic life didn't die? The American Prospect, 25, 17-20.

Smith, D., 1999. Poor marketing or the decline of altruism? Young people and volunteering in the UK. International Journal of Non-profit and Voluntary Sector Marketing, 4(4), 372-377.

Sport England, 2002. Sport volunteering in England: A summary report. Available from:

http://www.sportengland.org/media/40052/valuing-volunteering-in-sport-in-englandsummary-report.pdf [accessed 20 May 2014].

Uggen, C. and Janikola, J., 1999. Volunteerism and arrest in the transition to adulthood. Social Forces, 78(1), 331-362.

Volunteering England, 2012. Free volunteering from red tape. Available from: http://www.volunteering.org.uk/policy-andcampaigns/policy-issues-redtape [accessed 13 December 2013].

Weiss, M.R., and Stuntz, C.P., 2004. A little friendly competition: Peer relationships and psychosocial development in youth sports and physical activity contexts. In M.R. Weiss, ed., Developmental sport and exercise psychology: A lifespan perspective. Morgantown, WV: Fitness Information Technology, Inc., 165-196. 